DOI: http://doi.org/10.21698/simi.2018.ab37

\title{
NEW CHROMATOGRAPHIC METHOD FOR DETERMINATION OF PARA-HYDROXY-BENZOIC ACID ESTERS FROM SEWAGE SLUDGE
}

\author{
Vasile-Ion Iancu*1, $^{* 1}$, Jana Petre ${ }^{1}$, Mariana Popescu ${ }^{1}$, Gabriel-Lucian Radu ${ }^{2}$ \\ ${ }^{1}$ National Research and Development Institute for Industrial Ecology-ECOIND, 71-73 Drumul \\ Podu Dambovitei, district 6, 060652, Bucharest, vasileiancu10@gmail.com, Romania \\ ${ }^{2}$ University Politehnica Bucharest, Faculty of Applied Chemistry and Materials Science, 1-7 \\ Polizu, 011061, Bucharest, Romania
}

Keywords: liquid chromatography-mass spectrometry, parabens, sludge, ultrasonic extraction

\section{Introduction}

Thus, this study was performed to obtain the first Romanian research regarding parabens occurrence in WWTP sludge. Such analytical investigation provides important baseline concentration data for the assessment of potential environmental effects from exposure to parabens in soil. The objective of this study was to develop a new and sensitive method for identification and quantification of some parabens using ultrasonic extraction followed by LC-MS/MS and to study their occurrence in sewage sludge samples from urban WWTP.

\section{Materials and methods}

A lyophilized sludge sample $(0.5 \mathrm{~g})$ was weighed into a glass baker and then $1 \mathrm{ml}$ of $50 \mu \mathrm{g} / \mathrm{L}$ internal standard was added. Sludge samples were introduced into centrifuge tubes where $5 \mathrm{~mL}$ of a mixture of methanol and acetone $(1: 1, \mathrm{v} / \mathrm{v})$ was then added. The obtained mixtures were placed in an ultrasonic for 15 minutes, after which they were centrifuged for 10 minutes at $3000 \mathrm{rpm}$. The supernatants obtained were transferred with a pipette to an extraction vial. The extraction process was repeated by adding $5 \mathrm{~mL}$ of the above solvent mixture and the obtained extracts were combined and then diluted with $100 \mathrm{~mL}$ ultrapure water. After that the diluted extract was purified on Strata X cartridges $(500 \mathrm{mg}, 6 \mathrm{~mL}$ ) using the Auto Trace 280 automated solid phase extraction (SPE) system, was used. Determination of parabens was performed with an Agilent 1260 series UHPLC system, which was constituted of a column thermostat, autosampler and a binary pump coupled with an Agilent 6410B triple quadrupole mass spectrometer with electro-spray ionization (ESI). Data acquisition and analysis were performed using Mass Hunter software. The chromatographic column was Hypersil Gold C18 $(2.1 \times 100 \mathrm{~mm}, 3 \mu \mathrm{m})$ from Thermo Scientific and the injection volume was $10 \mu \mathrm{L}$. The mobile phase rate (composed by acetonitrile and $0.01 \%$ acid acetic) was $0.2 \mathrm{ml} / \mathrm{min}$ and the column temperature was kept at $18^{\circ} \mathrm{C}$. For the separation of analytes, we used a mobile phase gradient elution. The MS optimum negative ionization parameters were: gas temperature, $300{ }^{\circ} \mathrm{C}$, gas flow, $6 \mathrm{~L} / \mathrm{min}$, capillary voltage, $4000 \mathrm{~V}$, nebulizer pressure, $40 \mathrm{psi}$. 


\section{INTERNATIONAL SYMPOSIUM "THE ENVIRONMENT AND THE INDUSTRY", SIMI 2018, BOOK OF ABSTRACTS}

\section{Results and conclusions}

The analysis method has been validated for sludge in terms of: linearity, limits of quantification, precision, accuracy. The calibration curves were plotted at 6 points in the operating range of $1 \mu \mathrm{g} / \mathrm{L}-100 \mu \mathrm{g} / \mathrm{L}$. A very good linearity was observed for all compounds in the linear concentration range of $\mathrm{R}^{2}$ ranging between $99.59 \%$ and $99.98 \%$. RSD values obtained for repeatability ranged from $3.4 \%$ to $7.4 \%$ for all compounds. For intermediate precision experiments RSD was below 14.5\%. Results obtained from repeatability and precision intermediate precision experiments indicate that the method is reproducible. The recovery results obtained for parabens that ranged from 71.1 to $109 \%$ with relative standard deviation (RSD) $<14 \%$.

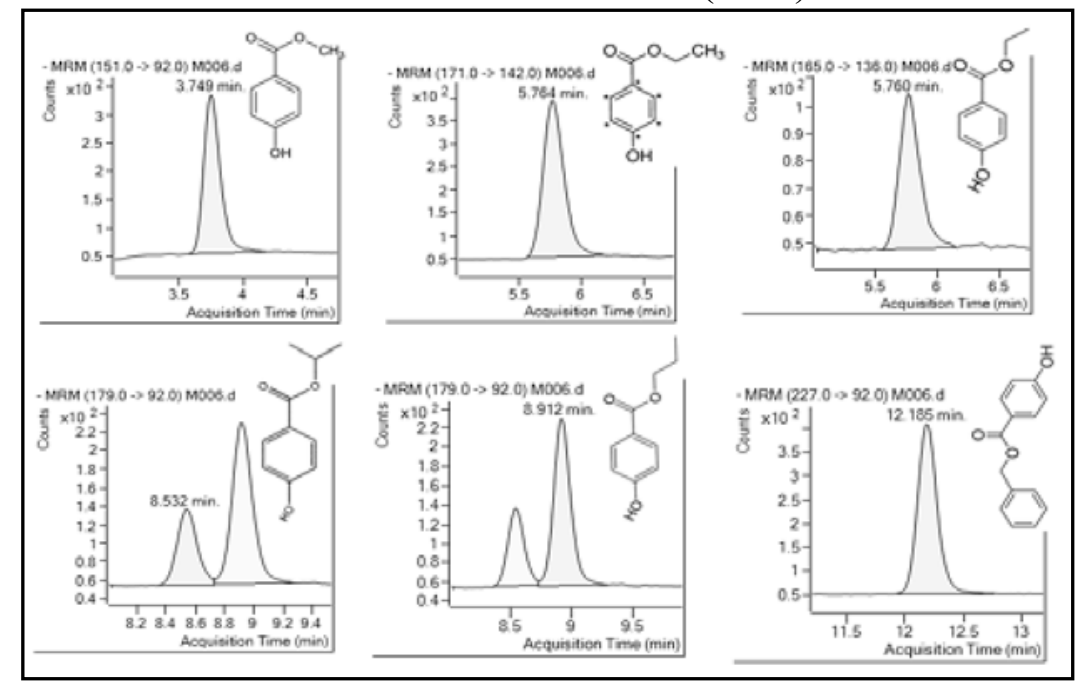

MRM transitions obtained for a solution containing from left to right: MPB, EPB, EPB-ring13C6 (IS), IPB, PB, BPB

Performance parameters

\begin{tabular}{|c|c|c|c|c|c|c|c|}
\hline \multirow{2}{*}{ Compound } & \multirow{2}{*}{$\mathrm{R}^{2}$} & \multirow{2}{*}{$\begin{array}{c}\text { Calibration } \\
\text { range }(\mu \mathrm{g} / \mathrm{L})\end{array}$} & \multirow{2}{*}{$\begin{array}{c}\text { Recovery } \\
\text { rate } \pm \text { RSD } \\
(\%)\end{array}$} & \multicolumn{2}{|c|}{ Precision $(\%)$} & \multirow{2}{*}{$\begin{array}{c}\text { IQL } \\
(\mu \mathrm{g} / \mathrm{L})\end{array}$} & \multirow{2}{*}{$\begin{array}{l}\mathrm{LOC} \\
\mathrm{ng} / \mathrm{g}\end{array}$} \\
\hline & & & & $\begin{array}{c}\text { intra- } \\
\text { day }\end{array}$ & $\begin{array}{l}\text { inter } \\
\text {-day }\end{array}$ & & \\
\hline MPB & 0.9959 & $1-100$ & $109 \pm 14$ & 3.7 & 14.5 & 0.5 & 1 \\
\hline EPB & 0.9998 & $1-100$ & $103.1 \pm 9$ & 3.4 & 9.4 & 0.6 & 1.2 \\
\hline IPB & 0.9966 & $1-100$ & $87.1 \pm 9$ & 6.3 & 8.8 & 0.5 & 1 \\
\hline PPB & 0.9969 & $1-100$ & $74.5 \pm 13$ & 7.4 & 13.1 & 1 & 2 \\
\hline BPB & 0.9976 & $1-100$ & $71.2 \pm 10$ & 6.5 & 9.7 & 0.2 & 0.4 \\
\hline
\end{tabular}

The method was successfully applied to real sludge samples collected from a municipal WWTP. Results showed the omnipresence of MPB and EPB at ng/g levels in all samples which were detected with average concentration of $15.3 \mathrm{ng} / \mathrm{g} \mathrm{d}$.w. and $3.7 \mathrm{ng} / \mathrm{g}$ d.w. The IPB and PPB were detected with average concentration of $3.3 \mathrm{ng} /$ d.w. and $4.4 \mathrm{ng} / \mathrm{g}$ d.w. 